\title{
Call for Special Issue Papers: Effectiveness, Implementation and Dissemination Research in Integrative Health
}

\section{Deadline for Manuscript Submission: May 31, 2020}

Guest Editors: A. Rani Elwy, PhD, Jeffrey Dusek, PhD, and Stephanie L. Taylor, PhD, MPH

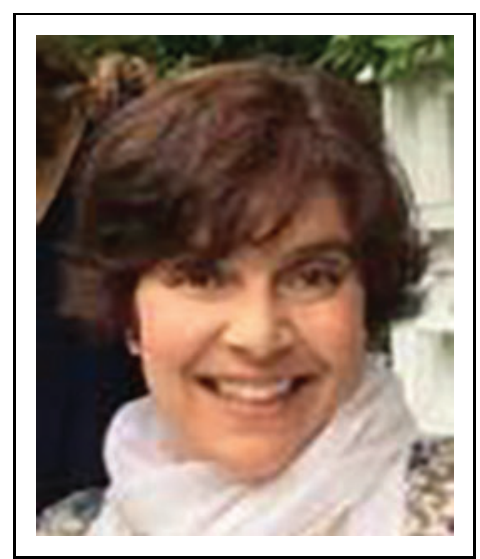

A. Rani Elwy, PhD Associate Professor, and Director, Implementation Science Core Department of Psychiatry and Human Behavior Alpert Medical School of Brown University; and VA Center for Healthcare Organization and Implementation Research

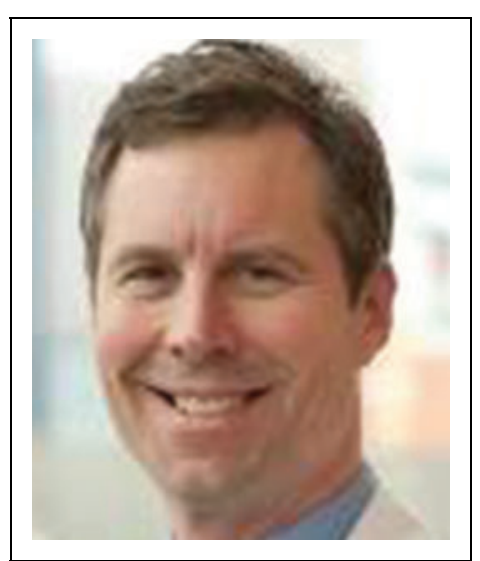

Jeffrey Dusek, PhD Director of Research, University Hospitals Connor Integrative Health Network Associate Professor, Department of Family Medicine and Community Health, Case Western Reserve University

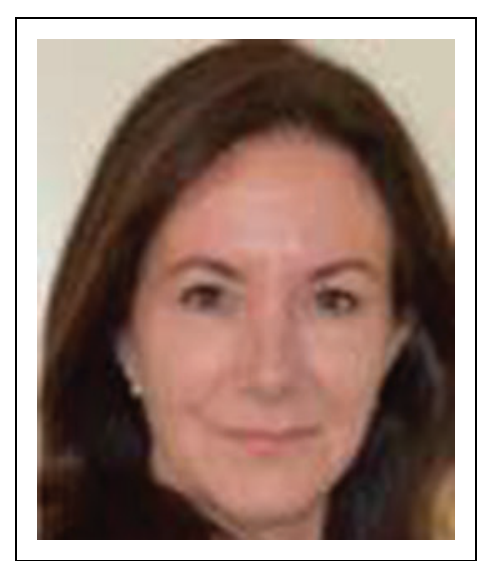

Stephanie L. Taylor, PhD, MPH Director, QUERI Complementary and Integrative Health Evaluation Center Veteran's Administration; Adjunct Associate Professor, Department of Health Policy and Management, UCLA

Thanks to generous grants from the George Family Foundation and the Institute for Integrative Health, all articles published in this issue will be open access.

Philanthropic Partners

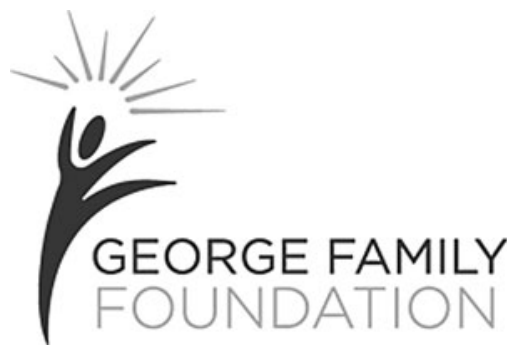

THE INSTITUTE FOR I NTEGRATIVE HEALTH 
Special Issue Advisory Team

Linda E. Carlson, PhD, RPsych

Enbridge Research Chair in Psychosocial Oncology

Professor, Department of Oncology, Cumming School

of Medicine, University of Calgary

Dave Clark, DrPH

Program Director, Extramural Research, National Center for Complementary and Integrative Health, NIH

Lynn DeBar, PhD, MPH [INVITED]

Senior Investigator, Kaiser Permanente Washington

Health Research Institute

Christine Goertz, DC, PhD

Professor, Duke University Medical School

Chair, Board of Governors, Patient-Centers

Outcomes Research Institute

Patricia Herman, ND, PhD, MS

Senior Behavioral and Social Scientist

RAND Corporation

Donald Douglas McGeary, MD

Associate Professor, Psychiatry

University of Texas Health Sciences
Dan Rhon, PT, DPT, DSc, OCS, FAAOMPT

Research Director, Bellin College

Amie Steel, ND, PhD

Complementary and Alternative Medicine

University of Technology, Sydney

Claudia Witt, MD, MBA

Vice Dean for Interprofessionalism, University of Zurich; Professor and Chair, Institute for Complementary and Integrative Medicine; University Hospital Zurich and University Zurich, Switzerland

Stephen Zeliadt, PhD, MPH

Research Professor Health Services, School of Public

Health, University of Washington; Veteran's

Administration Health Services Research

and Development

Suzanna Zick, ND, MPH

Research Associate Professor

Co-director, Integrative Family Medicine

University of Michigan

Medical School

The importance of real-world research to help the public, academics, decision makers and other stakeholders understand the optimal uses of complementary and integrative health practices and practitioners has never been as important as it is today. A crisis in treatment of people with chronic pain and high levels of public use drives interest in non-pharmacologic approaches to pain and symptom management. Putting patients at the center of research and dissemination can drive practical models. Meantime, the WHO's Traditional, Complementary and Integrative Medicine initiative urges member nations to determine how these approaches can be useful in meeting the WHO goal of universal health care. In fact, this priority is enshrined in the mandate that established the USA's National Center for Complementary and Integrative Health $(\mathrm{NCClH})$ : “ ... study the integration of alternative treatment, diagnostic and prevention systems, modalities, and disciplines with the practice of conventional medicine as a complement to such medicine and into health care delivery systems." Decision makers need to know what interventions are effective and how to disseminate and sustainably implement evidence-based integrative health practices.

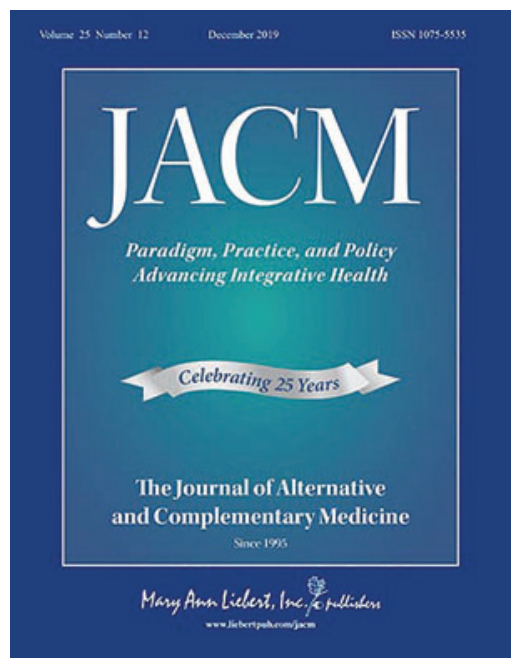

In October 2020, JACM: Paradigm, Practice and Policy Advancing Integrative Health (The Journal of Alternative and Complementary Medicine) will publish a Special Issue on Effectiveness, Implementation and Dissemination Research in Integrative Health. The goal of the Special Issue is to provide an enduring volume that will both aggregate the best of such research while also educating and prompting the field toward more robust engagement with implementation science and other forms of research that can guide new care models.

Guiding the special issue are guest editors Rani Elwy, PhD, Jeffery Dusek, PhD and Stephanie L. Taylor, PhD. Drs. Elwy and Taylor are implementation scientists who are leaders in the foundational efforts of the US Veteran's Administration to transform that agency into a "whole health" model that appropriately partners with integrative practices and practitioners. As such, Elwy and Taylor are in the thick of one the globe's most intentional efforts to implement new forms of integrative care. Dusek's background includes a decade and a half directing research dedicated to integrative strategies inside private not for profit health systems. Currently at the University Hospitals Connor Integrative Health Network, Dusek also continues to lead a practice-based research network of integrative academic health centers that are collaborating in similar, practical objectives. 
Timeliness with the NCCIH: JACM interest in developing this Special Issue coincides with activity at the NIH $\mathrm{NCClH}$ relative to implementation science. We are pleased and honored to have $\mathrm{NCClH}$ implementation science leader Dave Clark, DrPH on the Special Issue Advisory Team.

We invite your submissions! We are seeking original research and reviews in these areas: effectiveness research on integrative practices, dissemination and implementation articles, cost and business models issues, and education research. If you have ideas that you believe would be solid additions but are not explicitly called out here, please send us a query.

Manuscript submission due date: May 31, 2020. When submitting your paper, please select the "Special Issue Effectiveness, Implementation and Dissemination Research in Integrative Health" manuscript category to ensure it is considered for this special issue. Original manuscripts should be no longer than 3,000 words, and Systematic Reviews should be no longer than 4,500 words. Title, abstract, acknowledgments, disclosures, references, and figure/table legends do not count toward the word limit.

Additional feature: As an additional feature in this JACM Special Issue, we are accepting submissions of 500word commentaries to reflect on next steps for effectiveness, implementation and dissemination: controversies; unusual experiences (not case reports); models of care; educational models; etc. Those submitting need not have also submitted original research. We will select a set from those submitted that will be published together to capture the challenges and opportunities for this moment for the field.

If you have questions in this area, or ideas for other submissions that might strengthen the value of this special issue, please feel free to query us via JACM Editor-in-Chief John Weeks at jweeks.jacm @gmail.com.

Submit your paper for peer review online: http://mc.manuscriptcentral.com/jaltcompmed 